\title{
Introduktion till årgång 44
}

Den fyrtiofjärde årgången av Barnboken - tidskrift för barnlitteraturforskning präglas av tre större teman som tillsammans visar på bredden såväl i den nordiska barn- och ungdomslitteraturen som i forskningen om densamma. Under 2021 publicerade Barnboken 15 artiklar, varav majoriteten tillhörde något av årets tre teman om poesi, tystnader och tystanden respektive översättning. Därtill publicerades 15 recensioner av aktuell nordisk och internationell teoretisk litteratur.

Årets största tema är "Poesi för barn och unga", redigerat av Johan Alfredsson (fil.dr, Göteborgs universitet) och Anne Skaret (professor, Høgskolen i Innlandet, Norge). I de sju artiklarna undersöks allt ifrån diktsamlingar, nonsensvers och bilderböcker till teateruppsättningar och poesi som ursprungligen riktats till en äldre målgrupp. Det sistnämnda är något som flera av bidragen intresserar sig särskilt för och analyserna åskådliggör hur poesin prövar och luckrar upp gränserna mellan de gängse kategorierna barn, ungdom och vuxen. Klassiska texter av exempelvis Tove Jansson och Barbro Lindgren behandlas, liksom nyare nordiska verk av författare och bildskapare som Ingvild Rishøi, Bendik Kaltenborn, Birgitte Krogsbøll och Kamilla Wichmann. Gästredaktörernas introduktion tecknar bakgrunden till temat och ger en närmare presentation av de sju bidragen.

Det andra gästtemat i årets volym är "Silence and Silencing in Children's Literature", sprunget ur IRSCL Congress 2019 vars tema var just tystnad och tystanden i barn- och ungdomslitteraturen. Gästredaktörer är konferensarrangörerna Elina Druker (professor, Stockholms universitet), Björn Sundmark (professor, Malmö universitet), Mia Österlund (docent, Åbo Akademi, Finland) och undertecknad. På grund av det stora intresset för temat sträcker det sig över två volymer och avrundas i årgång 44 med två bidrag som belyser barnbokens potential att utmana tystande strategier, i det ena fallet med hjälp av queerteoretiska verktyg och i det andra med utgångspunkt i djurrätt och tidigare forskning om djur i barnlitteraturen. Båda artiklarna, liksom de tidigare åtta bidrag som tillhör temat, beskrivs närmare i gästredaktörernas introduktion.

(C)2021 Åsa Warnqvist. This is an open access article distributed under the terms of the Creative Commons CC-BY-NC 4.0 License (https:/ / creativecommons.org/licenses/by-nc/4.0/), permitting all non-commercial use, distribution, and reproduction in any medium, provided the original work is properly cited.

Citation: Barnboken - tidskrift för barnlitteraturforskning/Barnboken: Journal of Children's Literature Research, Vol. 44, 2021 http://dx.doi.org/10.14811/clr.v44.645 
I de fem spontaninskickade bidrag som tillsammans har fått bilda temat "Översättning" granskas översatt barn- och ungdomslitteratur inom en rad genrer och språkområden. Anna Vogel undersöker hur tidsanda och produktionsvillkor påverkat hur huvudpersonen Anne Shirleys karaktärsdrag framställs i svenska översättningar av L. M. Montgomerys Anne of Green Gables (1908). Marcus Axelsson och Ragnhild Næsje analyserar tyska, franska och brittiska utgåvor av norska Maria Parrs böcker, med tonvikt lagd på omslag och titlar. Även i Marcus Axelsson och Charlotte Lindgrens artikel står Maria Parrs författarskap i centrum, då de tittar närmare på kraftuttryck i franska och svenska översättningar av Parrs Keeperen og havet (2017). Mari Mossberg har skrivit två bidrag till temat. I det första undersöker hon könsneutrala och inkluderande strategier i franska faktaböcker översatta till svenska. I sin andra artikel analyserar Mossberg den svenska översättningen av bestseller-fenomenet Good Night Stories for Rebel Girls. 100 Tales of Extraordinary Women (2016) av Elena Favilli och Francesca Cavallo, med utblickar mot de norska, danska och franska översättningarna. Det faktum att det skickades in hela fem spontanmanus till Barnboken som handlade om översättning ungefär samtidigt visar på det stora intresset för det här forskningsområdet i Norden.

Slutligen bjuder sektionen "Övrigt" på ett bidrag av Ulf Boëthius som sätter ljus på ett äldre verk av Erik Pallin med titeln Kaparkaptenen på Emden. Romantiserad skildring från det stora världskriget (1914). Boëthius belyser spänningarna mellan fakta och fiktion i Erik Pallins skildring av kriget. Analysen visar hur Pallin tonar ned snarare än framhäver verklighetens grymheter i sin roman, till förmån för en klassisk äventyrsberättelse med både humoristiska och romantiska inslag.

Barnboken är en Open Access-tidskrift, vilket innebär att artiklar och recensioner publiceras digitalt och är fritt tillgängliga på tidskriftens webbplats samt i fulltext via flera stora internationella databaser. Tidskriften har huvudsakligen svenskt och nordiskt fokus, men har läsare över hela världen. Redaktionen bestod under 2021 förutom av undertecknad av professor Maria Jönsson (Umeå universitet, Sverige), professor Anne Skaret (Høgskolen i Innlandet, Norge), professor Olle Widhe (Göteborgs universitet, Sverige) och docent Mia Österlund (Åbo Akademi, Finland). Recensionsredaktör är forskningsassistent Hanna Liljeqvist (Svenska barnboksinstitutet). I tidskriftens internationella Advisory Board ingår 15 framstående svenska, nordiska och internationella forskare. Tidskriften ges ut med stöd från Vetenskapsrådet. 
Under det gångna året har redaktionen glatts åt att antalet prenumeranter ökat samtidigt som vi även sett en ökning i antalet följare på tidskriftens Facebooksida. Barnboken - tidskrift för barnlitteraturforskning välkomnar både nya och gamla läsare att ta del av den engagerande och inspirerande forskning som presenteras $i$ årets volym.

\author{
Åsa Warnqvist \\ Huvudredaktör för
}

Barnboken - tidskrift för barnlitteraturforskning och forskningsledare vid Svenska barnboksinstitutet 